\title{
Semeadura direta de forrageiras de estação fria em campo natural com aplicação de herbicidas: I. Produção de forragem e contribuição relativa das espécies
}

\author{
No-till seeding of cool season forages on native pasture with herbicides application: \\ I. Forage yield and relative contribution of plant species.
}

\author{
Enrique Pérez Gomar ${ }^{2}$ José Miguel Reichert ${ }^{3}$ Dalvan José Reinert ${ }^{3}$ \\ Fernando García Prechac ${ }^{4}$ Elbio Berretta ${ }^{5}$ Claudia Marchesi $^{6}$
}

RESUMO

Os campos naturais apresentam estacionalidade na sua produção forrageira, a qual pode ser atenuada com a introdução de espécies de estação fria através de semeadura direta, aumentando a produção forrageira no inverno. Durante quatro anos, conduziu-se um experimento de semeadura direta de forragem de inverno, sobre campo nativo, em um Argissolo Vermelho-Amarelo, de textura superficial arenosa do norte do Uruguai. Em delineamento de blocos ao acaso com parcelas subsubdivididas, foram testadas doses de herbicidas (glifosate $1 \mathrm{~L}$ $h a^{-1}$, glifosate $4 L h^{-1}$, paraquat $3 L h^{-1}$ e testemunha), como tratamento principal, aplicadas no ano 1994. A repetição ou não das mesmas doses no ano 1995 constituiu-se na subparcela, e a aplicação ou não das mesmas doses no ano 1996 constituiu-se na sub-subparcela. Os resultados mostraram que o maior distúrbio sobre a produção de forrageiras e contribuição das espécies do campo nativo foi provocado com a aplicação continuada de herbicidas sistêmicos na maior dose. Quando não foi aplicado herbicida (testemunha) havia onze espécies e com

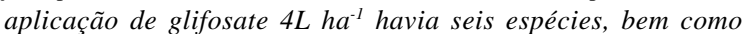
ocorreu uma substituição de espécies perenes por anuais. $O$ herbicida paraquat e a dose baixa de glifosate mostraram efeitos intermediários entre o observado no campo nativo semeado com triticale e azevém sem tratar com herbicida e os provocados com glifosate na dose alta. Por outro lado, os rendimentos de matéria seca das espécies forrageiras invernais semeadas foram $63 \%$ maiores na dose mais alta de glifosate do que na testemunha, devido a um maior controle da competição que exercia o campo nativo.
Palavras-chave: produção forrageira, semeadura direta, pastagem natural.

\section{ABSTRACT}

Natural grasslands have great seasonal fluctuation of forage production. The winter forage production may be increased using cool-season forage species established with notill, reducing seasonal fluctuations. An experiment with winter grasses (black oat and rye grass) no-till sown on native grasses, was conducted during four years on a fine-loamy, mixed, active Mollic Hapludalf, sandy A horizon, in northern Uruguay. The experimental design was split-splitplot on randomized blocks,

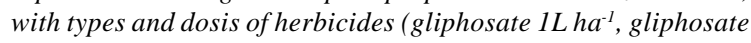

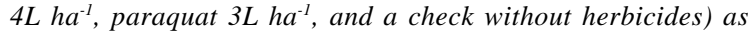
main treatments, applied in 1994. The application or not of the same treatments in 1995 constituted the splitplots, and their reapplication or not in 1996 constituted the split-splitplots.The results showed that the greatest disturbance on the botanical composition of the native grassland was caused with the application of the higher systemic herbicide dose every year. When herbicides were not applied, there were eleven species present, but with $4 \mathrm{~L} \mathrm{ha} \mathrm{h}^{-1}$ of glifosate every year there were only six species, as well as a substitution of perennial species by annual ones. The use of paraquat and the lower gliphosate dose showed intermediate effects between the native grassland without applied herbicides, and the treatment with the higher gliphosate dose. On the other hand, dry matter yield of the introduced winter forage species was $63 \%$ greater in the higher gliphosate dose than in the treatment without herbicide

${ }^{1}$ Parte da Dissertação de Mestrado do primeiro autor apresentada ao Programa de Pós-graduação em Agronomia, Universidade Federal de Santa Maria (UFSM). Parcialmente financiada pelo Pronex-CNPq/FINEP.

${ }^{2}$ Engenheiro Agrônomo, MSc, Pesquisador do Instituto Nacional de Investigación Agropecuaria del Uruguay (INIA). Ruta 5, Km 386,

Tacuarembó, Uruguay. E-mail: eperez@tb.inia.org.uy

${ }^{3}$ Engenheiro Agrônomo, PhD, Professor Titular do Departamento de Solos, UFSM, 97105-900, Santa Maria (RS). Pesquisador do CNPq. reichert@ccr.ufsm.br. Autor correspondente.

${ }^{4}$ Engenheiro Agrônomo, PhD, Profesor Titular da Facultad de Agronomía de la Universidad de la República, Garzón 780, Montevideo,

Uruguay. E-mail: fgarciap@fagro.edu.uy

${ }^{5}$ Engenheiro Agrônomo, PhD, Pesquisador do Instituto Nacional de Investigación Agropecuaria del Uruguay (INIA). Ruta 5, Km 386,

Tacuarembó, Uruguay. 
application, due to greater control of the competition by the native grasses.

Key words: forage production, no-tillage, native grasslands.

\section{INTRODUÇÃO}

O campo nativo desenvolvido sobre solos arenosos, na região norte do Uruguai e sul do Brasil, tem uma produção forrageira que se caracteriza por uma marcada estacionalidade. Essa é resultante da composição botânica das pastagens naturais que têm uma predominância de espécies estivais, que determinam níveis adequados de produção de forragem na época primavera-verão e severos déficits no período de estação fria.

A introdução de novas espécies numa comunidade vegetal requer condicionamento prévio para assegurar sucesso (CARÁMBULA et al., 1994; NABINGER, 1980). Busca-se melhorar o contato da semente com o solo e minimizar a competição da vegetação existente. Os mesmos autores indicam a necessidade de condicionamento do campo nativo para a sobre-semeadura de novas espécies, pois quanto mais complexa for a estrutura de uma comunidade, maior será a dificuldade que uma planta estranha tem em se estabelecer nela.

Assim, segundo CARÁMBULA et al. (1994), na medida que se tenta introduzir novas espécies nessas comunidades estabelecidas, necessariamente alterações ou distúrbios na comunidade serão provocados. Essas alterações podem ser provocadas mediante o sobrepastejo, a queima, o preparo do solo, a aplicação de herbicidas, ou as combinações das práticas mencionadas. Por outro lado, o ecossistema reage a esses distúrbios, provocando uma substituição de espécies (WHALLEY, 1994).

Quanto mais vigorosa e densa é uma comunidade vegetal, menores são as possibilidades de implantação das espécies semeadas (RISSO \& BERRETTA, 1996), enquanto que bons resultados da semeadura direta são alcançados quando o campo nativo encontra-se paralisado no momento da semeadura (MORAES, 1991). O autor faz referência à época do ano em que se faz a semeadura, associando-a com baixas temperaturas de fim de outono e ao começo das geadas. Conforme BERRETTA (1993), o uso do fogo ou a queima também apresenta efeito similar, controlando a competição do campo nativo no momento da semeadura. Da mesma forma, com o uso de altas pressões de pastejo consegue-se um adequado controle da vegetação permitindo a instalação das pastagens cultivadas (CARÁMBULA, 1977; GONÇALVES \& GIRARDI,
1986). Os herbicidas, segundo CARÁMBULA (1977), são utilizados para controlar a vegetação no momento da semeadura de forma semelhante às práticas de manejo antes mencionadas.

Os herbicidas utilizados são chamados herbicidas de manejo, segundo RODRIGUES (1985), aplicados sobre a cobertura vegetal, e têm a característica de serem não seletivos, podendo ser de contato (paraquat, diquat, entre outros) ou sistêmicos (glifosate, entre outros).

Na medida que a competição de algumas espécies é reduzida mediante a utilização de herbicidas e aproxime-se a uma monocultura, os máximos rendimentos das espécies introduzidas serão alcançados (MAGALHÃES, 1989). Por outro lado, o mesmo autor comenta que, em condições de competição, quando o campo nativo se encontra no momento de mínima produção e um dos fatores é colocado como não limitante, a fertilidade, por exemplo, promove-se o crescimento da parte aérea da espécie semeada, possibilitando uma dominância sobre as espécies nativas.

Em um trabalho com semeadura direta de pastagens anuais de inverno sobre campo nativo com diferentes doses dos herbicidas paraquat e glifosate, PÉREZ GOMAR et al. (1996) encontraram uma correlação positiva entre a produção de matéria seca e a magnitude de controle exercido pelos herbicidas. Os mesmos autores indicam que o efeito foi maior com herbicida sistêmico em relação ao de contato e, dentro de cada tipo, com maiores doses. Resultados similares são apresentados por CAVALHEIRO (1997) e por FERRI (1997), esse último trabalhando com doses de glifosate. Com o aumento na dose houve maior controle da vegetação e, por conseguinte, maior rendimento das espécies semeadas.

O objetivo deste trabalho foi o de verificar e medir o impacto do tipo e intensidade de controle da vegetação nativa por herbicidas para introdução de gramíneas de inverno e seus efeitos na composição botânica e na produção de matéria seca das pastagens.

\section{MATERIAL E MÉTODOS}

O experimento foi realizado no Instituto Nacional de Investigación Agropecuária (INIA), "La Magnolia”, Departamento de Tacuarembó, Uruguai. Geograficamente, a área encontra-se no paralelo $32^{\circ}$ de latitude sul. Climaticamente a região é definida como Cfa, mesotermal úmida de acordo com a classificação de Köppen, com uma temperatura média do mês mais frio menor que $18^{\circ} \mathrm{C}$, mas superior $\mathrm{a}-3^{\circ} \mathrm{C}$, e temperatura média do mês mais quente maior que $22^{\circ} \mathrm{C}$, ausência de estação seca e com uma 
precipitação maior de 30mm no mês mais seco do verão. O solo é um Argissolo Vermelho-Amarelo de textura franco arenosa no horizonte A (fine-loamy, mixed, active Mollic Hapludalf), sob pastagem natural constituída predominantemente de espécies de gramíneas estivais.

Utilizou-se o delineamento experimental em blocos ao acaso, com tratamentos arranjados em parcelas sub-subdivididas, com três repetições. As parcelas principais foram representadas pelos diferentes tratamentos com herbicidas (paraquat $3 \mathrm{~L}$ $\mathrm{ha}^{-1}$, glifosate $1 \mathrm{~L} \mathrm{ha}^{-1}$ e glifosate $4 \mathrm{~L} \mathrm{ha}^{-1}$ ) aplicados em 1994 e testemunha. As subparcelas foram a reaplicação ou não dos herbicidas em 1995, e as sub-subparcelas foram definidas pela reaplicação ou não dos herbicidas em 1996. Em 1997 as aplicações foram semelhantes às de 1996, permanecendo o delineamento em subsubparcelas. As parcelas principais mediram $10 \mathrm{~m} \mathrm{x}$ $15 \mathrm{~m}$, as subparcelas $5 \mathrm{~m} \times 15 \mathrm{~m}$ e as sub-subparcelas $5 \mathrm{~m} \times 7,5 \mathrm{~m}$.

Os herbicidas utilizados foram glifosate e paraquat. Para glifosate, o produto comercial utilizado foi o Roundup que apresenta uma concentração de $360 \mathrm{~g} \mathrm{~L}^{-1}$ de equivalente ácido, e as doses utilizadas foram de 1 e $4 \mathrm{~L} \mathrm{ha}^{-1}$ de produto comercial. Para paraquat, o produto comercial utilizado foi Gramoxone, cuja formulação é uma solução aquosa concentrada de $200 \mathrm{~g} \mathrm{~L}^{-1}$ de ingrediente ativo, e a dose utilizada foi de $3 \mathrm{~L} \mathrm{ha}^{-1}$ de produto comercial.

Antes do início do experimento, a área vinha sendo pastejada por bovinos e ovinos. Nos anos de 1994 e 1995, uma mistura de $130 \mathrm{~kg} \mathrm{ha}^{-1}$ de aveia preta (Avena strigosa L.) e $20 \mathrm{~kg} \mathrm{ha}^{-1}$ de azevém (Lolium multiflorum L.) foi semeada em semeadura direta, enquanto que, nos anos de 1996 e 1997, a mistura utilizada foi de $140 \mathrm{~kg} \mathrm{ha}^{-1}$ de triticale $(\boldsymbol{X}$ Triticosecale Wittmack) e $20 \mathrm{~kg} \mathrm{ha}^{-1}$ de azevém. A adubação em todos os anos consistiu em $40 \mathrm{~kg} \mathrm{ha}^{-1} \mathrm{de}$ nitrogênio e $80 \mathrm{~kg} \mathrm{ha}^{-1}$ de fósforo, aplicados na semeadura, e $60 \mathrm{~kg} \mathrm{ha}^{-1}$ de nitrogênio, no perfilhamento. Não foi aplicado corretivo no solo (calcário), nem adubação potássica. No ano de 1997, a aplicação dos tratamentos de herbicidas ocorreu no dia 28/04 e a semeadura realizada no dia 07/05.

A área experimental foi manejada com exclusão de animais, tanto durante o ciclo de crescimento da pastagem instalada como ao final de cada período de crescimento da mesma. Antes da aplicação dos herbicidas, realizava-se uma roçada com a finalidade de homogeneizar a altura da cobertura vegetal. A produção de matéria seca das espécies invernais introduzidas (triticale e azevém) foi determinada no dia 23/09/97, através de cortes com tesoura efetuados a $5 \mathrm{~cm}$ do nível do solo, em uma superfície de 20 x $30 \mathrm{~cm}$ em três locais dentro de cada parcela. $\mathrm{O}$ material foi secado a $60^{\circ} \mathrm{C}$ até peso constante. A produção estival de matéria seca das espécies espontâneas foi determinada através de corte efetuado, segundo a mesma metodologia, no dia 20/ 03/98. Após cada corte, toda área foi roçada a $5 \mathrm{~cm}$ do nível do solo para uniformizar a altura da vegetação.

A composição botânica das espécies espontâneas foi realizada no mês de março de 1997 utilizando-se o método duplo metro (DAGET \& POISSONET, 1969). Em síntese, o método consiste em identificar as espécies que são tocadas com uma haste de aço de $30 \mathrm{~cm}$ de comprimento que é deslocada em intervalos de $10 \mathrm{~cm}$ sobre uma trena de $2 \mathrm{~m}$ estendida que define uma linha fixa.

A análise estatística constou da análise de contrastes ortogonais, mencionados a seguir.

a) Entre os tratamentos de 1994 (parcelas principais): 1) $\mathrm{T}$ vs $\mathrm{O}$ (testemunha versus outros): compara a média do tratamento sem herbicida contra a média das médias dos tratamentos que receberam herbicida (paraquat $3 \mathrm{~L} \mathrm{ha}^{-1}$; glifosate $1 \mathrm{~L} \mathrm{ha}^{-1}$; glifosate $4 \mathrm{~L} \mathrm{ha}{ }^{-1}$ ); 2) $\mathrm{P}$ vs $\mathrm{G}$ (paraquat $3 \mathrm{~L} \mathrm{ha}^{-1}$ versus glifosate 1L ha-1 e glifosate $4 \mathrm{~L} \mathrm{ha}^{-1}$ ): compara a média do tratamento que recebeu paraquat $3 \mathrm{~L} \mathrm{ha}^{-1} \mathrm{com}$ a média dos tratamentos que receberam glifosate (glifosate $1 \mathrm{~L}$ ha $^{-1}$ e glifosate $4 \mathrm{~L} \mathrm{ha}^{-1}$ ); 3 ) G1 vs G4 (glifosate $1 \mathrm{~L} \mathrm{ha}^{-}$ ${ }^{1}$ versus glifosate $4 \mathrm{~L} \mathrm{ha}^{-1}$ ): compara a média do tratamento que recebeu $1 \mathrm{~L} \mathrm{ha}^{-1}$ de glifosate com o que recebeu $4 \mathrm{~L} \mathrm{ha}^{-1}$ de glifosate.

b) Entre os tratamentos de 1995 (parcelas subdivididas): 4) 95 sim vs não: compara a média das médias dos sub-tratamentos que, em 95, receberam novamente o tratamento de 94 com a média dos tratamentos que não o receberam.

c) Entre os tratamentos de 1996 (parcelas subsubdivididas): 5) 96 sim vs não: compara os subsubtratamentos que, em 96, receberam o tratamento de 94 contra os que não o receberam.

d) Interações 94 x 95: 6) T vs O, 95 sim vs não: testa se houve uma mudança significativa na diferença explicada para o contraste 1 (1994) quando os tratamentos foram ou não repetidos em 1995; 7) P vs G, 95 sim vs não: testa se o contraste 2 mudou ao repetirem-se ou não os tratamentos em 1995; 8) G1 vs G4, 95 sim vs não: testa se o contraste 3 mudou ao repetirem-se ou não os tratamentos em 1995.

e) Interações 94 x 96: 9) $\mathrm{T}$ vs O, $96 \mathrm{sim}$ vs não: testa se o contraste 1 mudou ao repetir-se ou não os tratamentos de 1994 em 1996; 10) Pvs G, 96 sim vs não: testa se o contraste 2 mudou ao repetir-se ou não os tratamentos de 1994 em 1996; 11) G1 vs 
G4, 96 sim vs não: testa se o contraste 3 mudou ao repetirem-se ou não os tratamentos de 1994 em 1996.

f) Interações 95 x 96: 12) 95 sim vs não, 96 sim vs não: testa se as diferenças em aplicar ou não aplicar em 1995 foi alterada por aplicação ou não em 1996.

g) Interações 94 x 95 x 96: 13) $\mathrm{T}$ vs $\mathrm{O}, 95$ sim vs não, 96 sim vs não: testa se o contraste 6 mudou por terem-se aplicado novamente ou não os tratamentos de 94 em 96; 14) P vs G, 95 sim vs não, 96 sim vs não: testa se o contraste 7 mudou por teremse aplicado novamente ou não os tratamentos de 94 em 96; 15) G1 vs G4, 95 sim vs não, 96 sim vs não: testa se o contraste 8 mudou por terem-se aplicado novamente ou não os tratamentos de 94 em 96.

\section{RESULTADOS E DISCUSSÃO}

\section{Produção de matéria seca}

$\mathrm{O}$ uso de herbicidas resultou em maior produção forrageira (Figura 1, Tabela 1 e contraste 1), semelhantemente aos resultados obtidos, no mesmo experimento no ano de 1996, por PÉREZ GOMAR et al., (1996) e em experimentos realizados em solo arenoso em Santa Maria-RS (CAVALHEIRO, 1997; FERRI, 1997). Os tratamentos que tiveram aplicação de herbicida apresentaram um maior controle da vegetação do campo nativo e, por conseguinte, a competição exercida sobre as espécies semeadas foi menor, resultando em incrementos na produção de matéria seca.

Em relação ao uso continuado de herbicidas através dos anos, o efeito da aplicação realizada em 1996 e 1997 na produção forrageira foi muito significativo (contraste 5), encontrando-se também diferenças entre os tratamentos que receberam herbicida em 1995 em relação aos que não receberam (contraste 4). Em todas as situações em que se aplicaram herbicidas nos anos de 1996 e 1997, as produções superaram aqueles das parcelas sem aplicação de herbicidas.

O controle da vegetação antes da semeadura garante uma menor competição e, por conseguinte, assegura uma melhor implantação e produção. O maior efeito foi observado quando o herbicida utilizado era paraquat, pois, por ser um herbicida de contato, seu maior efeito é provocado imediatamente após a aplicação. Posteriormente, houve recuperação quase total das espécies de campo nativo, determinando a necessidade de realizar controle dessas espécies todos os anos para obter níveis de produção comparáveis aos obtidos com os tratamentos que receberam glifosate.

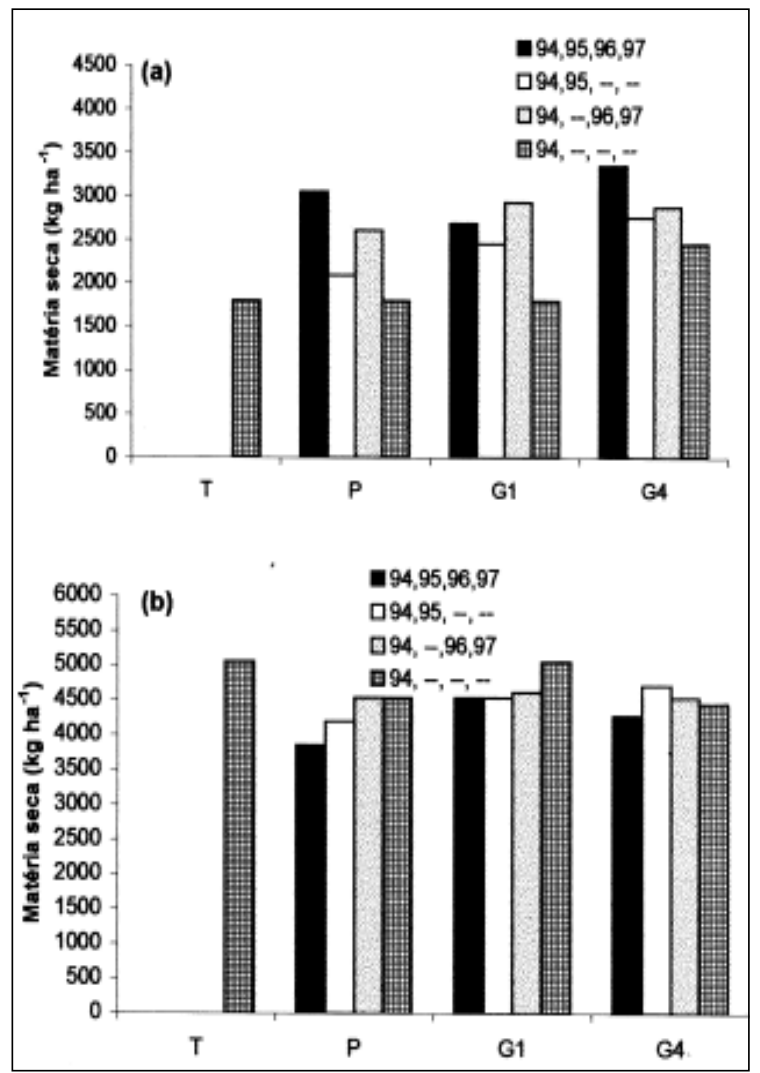

Figura 1 - Produção de matéria seca acumulada de triticale e azevém em 23/09/97 (a) e das espécies do campo nativo, no verão de 1997/98 (b), sob diferentes tratamentos de herbicidas aplicados em diferentes anos $(-$ - = sem aplicação, $\mathrm{T}=$ testemunha, $\mathrm{P}=$ paraquat, $\mathrm{G} 1=$ glifosate $1 \mathrm{~L} \mathrm{ha}^{-1}, \mathrm{G} 4=$ glifosate $4 \mathrm{~L}$ $\mathrm{ha}^{-1}$ ).

A menor dose $\left(1 \mathrm{~L} \mathrm{ha}^{-1}\right)$ de glifosate apresentou um comportamento similar ao observado para o paraquat. Quando se aplicou dose alta $\left(4 \mathrm{~L} \mathrm{ha}^{-1}\right)$ de glifosate, o efeito sobre as espécies de campo nativo foi maior, obtendo-se maior produção de matéria seca em relação a não aplicação, por haver aplicado o herbicida no ano de implantação. Os mesmos comentários são válidos quando se compara a aplicação ou não dos tratamentos de herbicidas no ano de 1995.

Apesar da menor produção da testemunha, esses níveis são aceitáveis, seguramente pela boa fertilização utilizada. Em outro trabalho no qual se estudou o efeito de nitrogênio na produção de matéria seca de triticale e azevém sob diferentes métodos de controle da vegetação, PÉREZ GOMAR et al. (1996) indicam que, quando não se aplicaram herbicidas para o controle da vegetação e não se adicionou nitrogênio, os níveis de produção eram muito baixos em relação à dessecação e adubação nitrogenada. 
Tabela 1 - Produção de matéria seca de triticale e azevém em 23/09/97, número de espécies presentes e frequiência relativa (\%) de espécies perenes sob diferentes tratamentos de herbicidas, aplicados em diferentes anos.

\begin{tabular}{|c|c|c|c|c|c|c|}
\hline \multirow[b]{2}{*}{ Ano } & \multirow[b]{2}{*}{ Aplicação } & \multicolumn{5}{|c|}{ Tratamento } \\
\hline & & $\mathrm{T}$ & $\mathrm{P}$ & G1 & G4 & Média \\
\hline & & \multicolumn{5}{|c|}{ Matéria seca, $\mathrm{kg} \mathrm{ha}^{-1}$} \\
\hline \multirow[t]{2}{*}{1994} & Sim & $1770 \mathrm{~b}$ & $2412 \mathrm{ab}$ & $2562 \mathrm{ab}$ & 2888 a & \\
\hline & Sim & 1770 & 2615 & 2609 & 3073 & 2517 a \\
\hline \multirow[t]{2}{*}{1995} & Não & 1770 & 2208 & 2357 & 2702 & $2259 \mathrm{~b}$ \\
\hline & Sim & 1770 & 2865 & 2809 & 3172 & $2661 \mathrm{a}$ \\
\hline \multirow[t]{2}{*}{1996} & Não & 1770 & 1958 & 2127 & 2603 & $2114 \mathrm{~b}$ \\
\hline & & \multicolumn{5}{|c|}{ Número de espécies presentes } \\
\hline 1994 & Sim & $11,00 \mathrm{a}$ & $6,33 \mathrm{~b}$ & $5,75 \mathrm{~b}$ & $5,50 \mathrm{~b}$ & \\
\hline \multirow{2}{*}{1995} & Sim & 11,00 & 6,16 & 6,16 & 5,83 & $7,12 \mathrm{a}$ \\
\hline & Não & 11,00 & 6,50 & 5,33 & 6,16 & $7,16 \mathrm{a}$ \\
\hline \multirow{2}{*}{1996} & Sim & 11,00 & 5,16 & 5,00 & 5,16 & $6,58 \mathrm{~b}$ \\
\hline & Não & 11,00 & 7,50 & 6,50 & 5,83 & $7,70 \mathrm{a}$ \\
\hline & & \multicolumn{5}{|c|}{ Frequiência relativa de espécies perenes } \\
\hline 1994 & Sim & 99,33 a & $94,50 \mathrm{ab}$ & $77,75 \mathrm{~b}$ & $54,25 \mathrm{c}$ & \\
\hline \multirow{2}{*}{1995} & Sim & 99,33 & 91,50 & 73,00 & 35,66 & $74,87 \mathrm{~b}$ \\
\hline & Não & 99,33 & 97,50 & 82,50 & 72,83 & $88,04 \mathrm{a}$ \\
\hline \multirow{2}{*}{1996} & Sim & 99,33 & 92,00 & 73,50 & 40,50 & $76,33 \mathrm{~b}$ \\
\hline & Não & 99,00 & 97,00 & 82,00 & 68,00 & $86,58 \mathrm{a}$ \\
\hline
\end{tabular}

( $\mathrm{T}=$ testemunha, $\mathrm{P}=$ paraquat, $\mathrm{G} 1=$ glifosate $1 \mathrm{~L} \mathrm{ha}^{-1}, \mathrm{G} 4=$ glifosate $4 \mathrm{~L} \mathrm{ha}^{-1}$ ).

Médias seguidas por mesma letra, nas linhas para T, P, G1 e G4 e na coluna, para cada ano, para as médias, não diferem significativamente (DMS, $\mathrm{p}<0,05)$.

No tratamento com glifosate $4 \mathrm{~L} \mathrm{ha}{ }^{-1}$ era esperado que ocorresse modificação na composição botânica, com marcado controle das espécies estivais e, portanto, menor produção de matéria seca no verão. No entanto, não se observaram diferenças significativas na produção de matéria seca (Figura 1), mas houve diferenças na composição botânica. Ocorreu uma substituição de espécies perenes do campo nativo por espécies anuais, que alcançaram bons níveis de produção. Cabe salientar que os níveis de fertilidade do solo foram adequados em função do efeito residual das adubações realizadas nas pastagens de inverno. Um exemplo claro disso foi a predominância de Digitaria sp, cuja freqüência foi de $70 \%$ naquelas parcelas que tiveram glifosate $4 \mathrm{~L} \mathrm{ha}^{-1}$ todos os anos e que apresentaram uma produção de matéria seca de $4359 \mathrm{~kg} \mathrm{ha}^{-1}$ comparada com $4667 \mathrm{~kg}$ $\mathrm{ha}^{-1}$ das parcelas de campo nativo sem herbicida.

\section{Composição botânica}

O efeito provocado pela aplicação de herbicidas no número de espécies é apresentado na figura 2 e na tabela 1 . Observa-se uma redução no número de espécies de 11 na testemunha, comparado com 6,3 para paraquat; 5,7 para glifosate $1 \mathrm{~L} \mathrm{ha}^{-1} \mathrm{e}$ 5,5 para glifosate $4 \mathrm{~L} \mathrm{ha}^{-1}$ (contraste 1 ). Esses resultados estão em concordância com os apresentados por BERRETTA E MARCHESI (1996), que mencionam que o número de espécies foi reduzido à metade quando foi aplicado glifosate $4 \mathrm{~L} \mathrm{ha}{ }^{-1} \mathrm{em}$ dois anos consecutivos. Por outro lado, houve tendência na redução do número de espécies quando foi usado o herbicida sistêmico em comparação ao de contato.

A diferença muito significativa exposta no contraste 5, que expressa redução no número de espécies pela aplicação de herbicida no ano 1996, 
manifesta-se claramente nos tratamentos que consideram a utilização de paraquat ou glifosate $1 \mathrm{~L}$ ha $^{-1}$ (Tabela 1). Quando a dose de glifosate utilizada foi de $4 \mathrm{~L} \mathrm{ha}^{-1}$, o efeito não foi tão visível. Isso pode ser explicado porque, com a aplicação de alta dose de glifosate, provoca-se uma severa alteração na composição botânica já no primeiro ano de aplicação. No entanto, com a dose baixa de glifosate ou com paraquat ocorre uma recuperação da pastagem, havendo a necessidade do controle anual da vegetação para a semeadura de espécies de estação fria.

Quando não se aplicaram herbicidas em 1995, mas sim em 1996/97, reduziu-se em aproximadamente dois o número de espécies (contraste 12). No entanto, quando foi aplicado em 1995, e não aplicado em 1996/97, não houve alteração no número de espécies.

A freqüência de espécies perenes na testemunha foi maior que nos tratamentos que receberam herbicidas (Figura 2 e Tabela 1). A composição botânica do campo nativo é predominantemente de espécies perenes estivais, as quais não foram alteradas pelo manejo de sobresemeadura de espécies anuais invernais sem aplicação de herbicidas. Quando foram aplicados herbicidas, houve uma substituição de espécies perenes por anuais, sendo que $99 \%$ das espécies foram perenes na testemunha, 94\% das mesmas foram perenes com aplicação de paraquat, $77 \%$ foram perenes com glifosate $1 \mathrm{~L} \mathrm{ha}^{-1}$ e $54 \%$ foram perenes com glifosate $4 \mathrm{~L} \mathrm{ha}^{-1}$.

Quando são comparados os dois herbicidas (contraste 2), observa-se que o paraquat não modificou substancialmente a composição das espécies (94\% das espécies são perenes), mas o glifosate causou uma diminuição na freqüência das espécies perenes $(65,5 \%)$. Por outro lado, quando são comparados os efeitos provocados pelo herbicida glifosate nas doses de 1 e $4 \mathrm{~L} \mathrm{ha}^{-1}$ (contraste 3 ), observa-se que o controle foi muito significativo, encontrando-se maior frequiência de espécies perenes para doses menores $(77 \%)$ em relação à maior dose (54\%) de glifosate.

Em relação ao uso contínuo de herbicidas através dos anos, a aplicação de herbicidas no ano 1995 (contraste 4) e aplicação de herbicidas no ano de 1996 (contraste 5) reduziu de forma muito significativa a incidência de espécies perenes em relação à não aplicação em ambos os anos.

Os contrastes 6,7 e 8 foram significativos, indicando que o uso de herbicidas versus o não uso, paraquat versus glifosate, e glifosate $1 \mathrm{~L} \mathrm{ha}^{-1}$ versus glifosate $4 \mathrm{~L} \mathrm{ha}^{-1}$ mostraram maiores diferenças quando
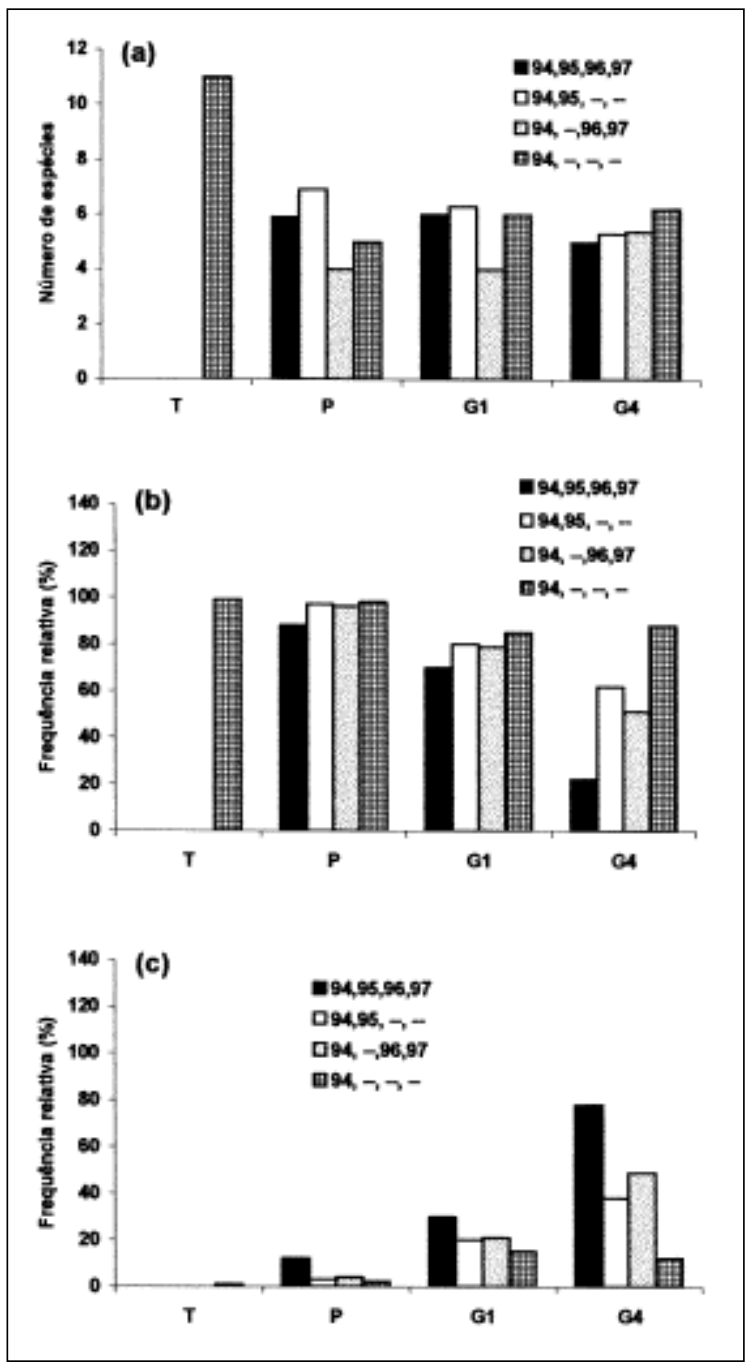

Figura 2 - Número de espécies presentes (a), frequência relativa de espécies perenes (b) e frequiência relativa de espécies anuais (c), sob diferentes tratamentos de herbicidas aplicados em diferentes anos (- - = sem aplicação, $\mathrm{T}=$ testemunha, $\mathrm{P}=$ paraquat, $\mathrm{G} 1=$ glifosate $1 \mathrm{~L} \mathrm{ha}^{-1}, \mathrm{G} 4=$ glifosate $\left.4 \mathrm{~L} \mathrm{ha}^{-1}\right)$.

o tratamento de 1994 repetiu-se em 1995 em relação à não reaplicação.

Com a redução de espécies perenes pela aplicação de herbicidas houve um aumento concomitante de espécies anuais (Figura 2). O maior efeito foi provocado pelo herbicida sistêmico. Não se observam diferenças significativas entre a contribuição de anuais na testemunha e no tratamento com paraquat.

O tratamento que provocou maior alteração foi o glifosate $4 \mathrm{~L} \mathrm{ha}^{-1}$. O tratamento glifosate $1 \mathrm{~L} \mathrm{ha}^{-1}$ não diferiu em forma significativa de paraquat. A aplicação de herbicidas tanto em 1995 como em 1996 
reduziu a contribuição de espécies perenes e aumentou a de espécies anuais.

\section{CONCLUSÕES}

Os níveis de produção de matéria seca das pastagens de estação fria introduzidas aumentaram com a diminuição da competição da vegetação nativa sobre as espécies introduzidas, devido à aplicação de herbicidas.

A produção total de forragem não foi afetada, apesar da substituição de gramíneas perenes por espécies anuais, especialmente nas maiores doses de herbicidas sistêmicos e menores intervalos de aplicação.

\section{REFERÊNCIAS BIBLIOGRÁFICAS}

BERRETTA, E.J. La quema como herramienta para el manejo del campo natural. Montevideo : INIA, 1993. 20p. (Hoja de Divulgación n.32)

BERRETTA, E.J.; MARCHESI, C. Evolución de la vegetación de un campo natural sobre suelos arenosos luego de dos años de siembra directa. Taquarembó : INIA, 1996. 40p. (Serie Actividades de Difusión n.105).

CARÁmbUla, M. Produción y manejo de pasturas sembradas. Montevideo : Hemisferio Sur, 1977. 463p.

CARÁMBULA, M. et al. Siembra de mejoramientos en cobertura. Montevideo : INIA, 1994. 20p. (Boletin de Divulgación n.46)

CAVALHEIRO, A.T. Sobressemeadura de aveia (Avena strigosa) + azevém em campo natural com e sem o uso de herbicidas. 1997. 78f. Dissertação (Mestrado em Zootecnia) Curso de Pós-graduação em Zootecnia, Universidade Federal de Santa Maria.

DAGET, P.; POISSONET, J. Une methode d'analyse phytologique des praries. Critries d'application. Ann Agronomiques, Emberger, v.22, p.5-41,1971.
FERRI, M.V.W. Semeadura direta de soja e aveia em campo nativo dessecado com herbicidas. 1997. 106f. Dissertação (Mestrado em Agronomia) - Programa de Pós-graduação em Agronomia, Universidade Federal de Santa Maria.

GONÇALVES, J.O.; GIRARDI, D. Efeito de três cargas animais sobre a vegetação de pastagem natural. Pesquisa Agropecuária Brasileira, v.21, n.5, p.547-554, 1986.

MAGALHÃES, A.C. Aspectos fisiológicos da associação entre gramíneas e leguminosas. Jaboticabal, 1989. In: SIMPÓSIO SOBRE ECOSSISTEMAS DE PASTAGENS, 1989, Jaboticabal. Anais... Jaboticabal : FUNEP, 1989. V.1, p.31-41.

MORAES, A. Produtividade animal e dinâmica de uma pastagem de pangola (Digitaria decumbens Stent), azevém (Lolium multiflorum Lam.) e trevo branco (Trifolium repens $\mathbf{L}$.), submetida a diferentes pressões de pastejo. 1991. 200f. Tese (Doutorado em Zootecnia) - Programa de Pós-graduação em Zootecnia, Universidade Federal do Rio Grande do Sul.

NABINGER, C. Técnicas de melhoramento de pastagens naturais no Rio Grande do Sul. 1980. In: SEMINÁRIO SOBRE PASTAGENS NATURAIS, 1980, Porto Alegre. Anais... Porto Alegre : FARSUL, 1980. V1, p.28-58.

PÉREZ GOMAR, E.; GARCIA, F.; MARCHESI, C. Siembra directa en sistemas basados en produciión de forraje: región nordeste. In: ___ Curso de actualizaçion sobre manejo y conservación de suelos. Montevideo : Facultad de Agr. da Universidad de la Republica, 1996. p.101-121.

RISSO, D.F.; BERRETTA, E.J. Mejoramiento de campos. In Curso de actualizaçion sobre manejo y conservación de suelos. Montevideo : Facultad de Agronomia da Universidad de la Republica, 1996. p.40-60.

RODRIGUES, B.N. Utilização de herbicidas em semeadura direta. In: _____ Atualização em semeadura direta. Campinas : Fundação Cargill, 1985. p.103-144.

WHALLEY, R.D.B. State and transition models for rangelands, successional theory and vegetation change. Tropical Grasslands, v.28, p.195-205,1994. 